\title{
24-h Movement Guidelines and Substance Use among Adolescents: A School-Based Cross-Sectional Study
}

\author{
Hugues Sampasa-Kanyinga ${ }^{1,2, *(\mathbb{D})}$, Ian Colman ${ }^{1,3} \mathbb{D}$, Gary S. Goldfield ${ }^{1,2}$, Ian Janssen ${ }^{4} \mathbb{D}$, JianLi Wang ${ }^{1,5}$, \\ Hayley A. Hamilton ${ }^{6,7}$ and Jean-Philippe Chaput ${ }^{1,2}$
}

1 School of Epidemiology and Public Health, University of Ottawa, Ottawa, ON K1N 6N5, Canada; icolman@uottawa.ca (I.C.); ggoldfield@cheo.on.ca (G.S.G.); JianLi.Wang@theroyal.ca (J.W.); jpchaput@cheo.on.ca (J.-P.C.)

2 Healthy Active Living and Obesity Research Group, Children's Hospital of Eastern Ontario Research Institute, Ottawa, ON K1H 8L1, Canada

3 Centre for Fertility and Health, Norwegian Institute of Public Health, P.O. Box 222 Skøyen, $\mathrm{N}-0213$ Oslo, Norway

4 School of Kinesiology and Health Studies, Queen's University, Kingston, ON K7L 3N6, Canada; ian.janssen@queensu.ca

5 Institute of Mental Health Research, University of Ottawa, Ottawa, ON K1N 6N5, Canada

6 Institute for Mental Health Policy Research, Centre for Addiction and Mental Health, Toronto, ON M5S 2S1, Canada; hayley.hamilton@camh.ca

check for updates

Citation: Sampasa-Kanyinga, $\mathrm{H}$.; Colman, I.; Goldfield, G.S.; Janssen, I.; Wang, J.; Hamilton, H.A.; Chaput, J.-P. 24-h Movement Guidelines and Substance Use among Adolescents: A School-Based Cross-Sectional Study. Int. J. Environ. Res. Public Health 2021, 18, 3309. https://doi.org/10.3390/ ijerph18063309

Academic Editors: José Enrique Moral-García, Sergio López-García, Eliseo García-Cantó and Cristian Abelairas-Gómez

Received: 16 February 2021

Accepted: 18 March 2021

Published: 23 March 2021

Publisher's Note: MDPI stays neutral with regard to jurisdictional claims in published maps and institutional affiliations.

Copyright: (C) 2021 by the authors Licensee MDPI, Basel, Switzerland. This article is an open access article distributed under the terms and conditions of the Creative Commons Attribution (CC BY) license (https:// creativecommons.org/licenses/by/ $4.0 /)$.
7 Dalla Lana School of Public Health, University of Toronto, Toronto, ON K1N 6N5, Canada

* Correspondence: hsampasa@uottawa.ca; Tel.: +1-613-562-5800

Abstract: Children and youth are recommended to achieve at least $60 \mathrm{~min} /$ day of moderate-tovigorous physical activity, no more than $2 \mathrm{~h}$ /day of recreational screen time, and a sleep duration of 9-11 h/night for 11-13-year-olds or 8-10 h/night for 14-17-year-olds. Meeting the physical activity, screen time, and sleep duration recommendations have previously been associated with substance use among adolescents. However, previous research has mainly examined these factors individually rather than looking at how these indicators could concurrently relate to substance use in this age group. Therefore, this study examined the associations between meeting the 24-h movement guidelines for screen time, sleep duration, and physical activity (independent variables) with substance use outcomes including alcohol consumption, cannabis use, and cigarette smoking (dependent variables) among adolescents. Self-reported data from a cross-sectional and representative sample of 10,236 students (mean age $=15.1$ years) in Ontario, Canada were analyzed. Logistic regression models stratified by gender were adjusted for potential confounders. Combinations of 24-h movement guidelines was differentially associated with substance use in boys and girls. Overall, findings showed that meeting 24-h movement guidelines is associated with lower odds of alcohol consumption, cannabis use, and cigarette smoking differentially with type of recommendation met and gender. Given that the associations between 24-h movement guidelines and substance use differ between boys and girls, future efforts should take this into consideration.

Keywords: screen time; sleep duration; physical activity; alcohol consumption; cigarette smoking; cannabis use; teenagers

\section{Introduction}

Substance use in adolescence is a major public health problem around the world. It is often initiated in adolescence and continues into adulthood [1]. Tobacco, alcohol, and cannabis are among the substances commonly misused by adolescents [1]. Smoking is a preventable cause of illness and death [2]. It is associated with a higher risk of several cancers, respiratory diseases, heart disease, and strokes. A recent study using World Health Organization data on tobacco use among adolescents aged 13-15 years documented a prevalence of tobacco use of $19.3 \%$ [3]. Alcohol is the most commonly consumed substance 
by adolescents [4], and it has several adverse health effects, including loss of coordination, memory loss, and liver damage. It can also affect behavior and decision-making. Alcohol poisoning can cause adolescents to engage in other risky behaviors, such as impaired driving, drug use, and risky sexual behavior [5]. Alcohol consumption also increases the risk of unintentional injuries, which are the leading cause of death among adolescents [6]. The prevalence of past-year alcohol use among Canadian students in grades 7 through 12 for 2016-2017 was 44\% [7]. Cannabis use impairs decision-making skills and judgment and can lead to negative results. It can also be addictive and is associated with harms such as withdrawal symptoms, depression, overdose, and even death [8]. Research indicated a significant increase in the use of cannabis among adolescents in 2017, as their perception of risk decreased [9]. An estimated one in 5 (22\%) students in grades 7 through 12 across Ontario, Canada used cannabis in 2019 [10]. Identifying important factors that could reduce the risk of substance use is important to inform prevention efforts.

Some factors that have received greater attention over the past decades are physical activity, screen time, and sleep duration. In general, active living and sufficient sleep duration have many health benefits and contribute substantially to the quality of life across the lifespan [11-14]. More specifically, physical activity, screen time, and sleep duration have been associated with the use of a variety of substances such as cigarette, alcohol, and cannabis $[15,16]$. For example, Ströhle et al. [17] found that adolescents who exercised daily or several times per week had a reduced prevalence of having any substance use disorder in the past 12 months compared with adolescents who exercised $\leq 1$ time per month. Studies have also shown that excessive screen time is associated with greater risk of substance use among adolescents [18,19]. Pasch et al. [20] found that short sleep duration prospectively predicted adolescents' cigarette, alcohol, and marijuana use in a sample of 704 US adolescents. Short sleep duration has also been associated with alcohol consumption and cannabis use in adolescents [21].

However, these lifestyle behaviors (i.e., physical activity, screen time, and sleep duration) have often been examined in isolation, ignoring how they interact with each other. The Canadian 24-h Movement Guidelines for Children and Youth account for the interaction and codependence between physical activity, sedentary behavior, and sleep [22]. The guidelines contain specific recommendations on the time that 5- to 17-year-olds should spend in moderate-to-vigorous physical activity (MVPA; at least $60 \mathrm{~min}$ per day), no more than $2 \mathrm{~h}$ of recreational screen time per day, and a sleep duration of 9 to $11 \mathrm{~h}$ per night for 5to 13 -year-olds, and 8 to $10 \mathrm{~h} / \mathrm{night}$ for 14- to 17-year-olds to support health benefits [22]. It is estimated that 3 to $10 \%$ of adolescents meet all three recommendations [23-28]. This is troubling because children and youth who meet all 3 recommendations are more likely to have better cognitive function [25], less impulsivity [29], lower odds of obesity [27], better dietary patterns [30], enhanced quality of life [31], and fewer depressive symptoms [23,24] than children who meet none of the recommendations.

Research has indicated that boys are more likely than girls to engage in some types of substance use, and previous studies have found important gender differences in the relationship between physical activity and alcohol consumption, cannabis use, and cigarette smoking [32]. Recently, Knell et al. [23] documented that compliance to all three recommendations was related to greater odds of smoking cigarettes and lower odds of cannabis use among US male adolescents; whereas among females, it was associated with lower odds of alcohol consumption. Contrary to our study, Knell et al. did not examine the intermediate combinations of meeting the physical activity, screen time, and sleep duration recommendations.

Most research studies have mainly examined the associations between physical activity, screen time, and sleep duration and substance use among adolescents individually rather than looking at how these indicators could concurrently relate to substance use in this age group. However, the relationships between different combinations of movement behaviors and substance use among adolescents is largely unknown. It is thus unknown whether adhering to all or certain combinations of guideline recommendations is associ- 
ated with a better substance use profile among adolescents. Gaining such knowledge is important because substance use, such as alcohol consumption, cannabis use, and cigarette smoking are of particular concern among adolescents $[4,33]$, they account for a substantial proportion of the global burden of disease in terms of disability-adjusted life years [34], and they cluster together with other unhealthy behaviors (e.g., lack of physical activity, unhealthy eating, etc.) within individuals [35-38].

To address this knowledge gap, and to inform public health efforts against adolescent substance use, the present study examined the associations between adherence to the recommendations in the Canadian 24-h Movement Guidelines and substance use among adolescents. It was hypothesized that adherence to the Canadian 24-h Movement Guidelines would be associated with lower substance use among adolescents, particularly among boys and younger adolescents because they tend to meet the guidelines more frequently than girls and older adolescents.

\section{Materials and Methods}

Data from the 2017 cycle of the Ontario Student Drug Use and Health Survey (OSDUHS, Canada) were analyzed. The OSDUHS is a biennial cross-sectional survey of Ontario students enrolled in grades 7 through 12 (aged 11 to 20 years or over) in publicly funded schools, representing nearly $93 \%$ of the Ontario adolescent population [4]. The survey uses a complex design. Within a selected school, classes are randomly selected within grades and all students in selected classes are asked to complete a self-administered paper-and-pencil questionnaire during a regularly scheduled classroom period. In total, 11,435 students in grades 7-12 from 764 classes across 214 schools completed the 2017 cycle of the survey. Response rates among schools, classes, and students were $61 \%, 94 \%$, and $61 \%$, respectively. Absenteeism accounted for $11 \%$ of the non-participation rate and parental or student refusal or unreturned consent forms accounted for $26 \%$. All subjects gave their signed assent in addition to parentally signed consent for those aged under 18 years before they participated in the study. The study was conducted in accordance with the Declaration of Helsinki, and the protocol was approved by the Research Ethics Boards at the Centre for Addiction and Mental Health and York University, as well as 31 school board research review committees. Detailed information on the OSDUHS are provided elsewhere [4].

\subsection{Measures}

\subsubsection{Independent Variables}

The measures for individual movement behaviors were obtained from the Centre for Disease Control (CDC)'s Youth Risk Behavior Survey (YRBS) [39].

Physical activity was measured using an item that asked students how many of the last 7 days they were physically active for at least $60 \mathrm{~min}$ each day. Students were asked to (1) add up all the time they spent in any types of physical activity that increased their heart rate and made them breathe hard some of the time (such as biking, running, brisk walking, dancing, rollerblading, football, soccer, skateboarding, basketball, and swimming); and (2) to include both school and non-school activities. Response options ranged from 0 to 7 days. For analysis, "7 days" corresponded to students that met the physical activity guideline recommendation [22]. The remaining responses were combined to represent those who did not meet the physical activity recommendation. This self-reported measure has shown good validity in comparison with accelerometry measures among children and adolescents [40].

Screen time was assessed using an item that asked students to indicate how many hours a day, on average, they spend watching TV/movies/videos, texting, playing video/ computer games, emailing, or surfing the Internet in their free time. Spending no more than $2 \mathrm{~h}$ per day of screen time represented adherence to the screen time recommendation [22]. Not meeting the screen time recommendation represented a screen time of more than $2 \mathrm{~h}$ 
per day. Measures of recreational screen time have also demonstrated good psychometric properties in this age group [41,42].

Sleep duration was assessed using a question that asked on an average school night, how many hours of sleep do students get. A binary variable was created defining adherence to the sleep duration based on the recommended range (9-11 $\mathrm{h}$ per night for 11-13-yearolds; $8-10 \mathrm{~h}$ per night for $14-17$-year-olds, or $7-9 \mathrm{~h}$ per night for those aged 18 years or older), contrasting with getting insufficient sleep [14,22]. This self-reported measure of sleep duration has shown good validity and reliability among children and adolescents [43].

\subsubsection{Outcome Variables}

Similar to the independent variables of physical activity, screen time, and sleep duration, outcome measures were also derived from the CDC's YRBS [39]. Alcohol use was measured with a question that asked students how often they drink alcohol (liquor, wine, beer, coolers) over the past 12 months. Tobacco use was measured with an item that asked students how often they smoke cigarettes over the past 12 months. Cannabis use was measured with a question that asked students how often they use cannabis (e.g., "marijuana") over the past 12 months. For all three, responses were dichotomized, contrasting substance use at least once vs. non-use over the past 12 months. Participants who indicated that they had a few puffs for tobacco cigarette or consumed a sip for alcohol were included in the non-use group, because a few puffs of tobacco cigarette and a sip of alcohol are different from regular use of these substances. A sensitivity analysis using a different cut-off (i.e., a high level of substance use) was run to contrast "regular use" vs. "non-regular use." Specifically, regular substance use was defined as at least 3 to 5 cigarettes smoking/day, at least 2 or 3 times a month of alcohol consumption, and 6 to 9 times of cannabis use in the last 12 months and were contrasted to the respective non-regular substance use.

\subsubsection{Covariates}

Covariates included age, ethnicity, gender, body mass index (BMI) $z$-score, and subjective socioeconomic status (SES). Age was measured in years, gender determined by being boy or girl, and ethnicity captured different ethnoracial backgrounds, including White, Black, East and South-East Asian, South Asian, and Other. Subjective SES was assessed using an adapted version of the MacArthur Scale of Subjective Social Status [44]. Students self-reported their body weight (kilograms) and height (meters). We calculated $\operatorname{BMI}\left(\mathrm{km} / \mathrm{m}^{2}\right)$ and converted it into $z$-scores following the World Health Organization's reference data [45].

\subsection{Statistical Analysis}

Participant characteristics were described via proportions and means. A Pearson's $\chi^{2}$ test adjusted for the complex survey design (for categorical variables) and an adjusted Wald test were used to test (for continuous variables) the statistical differences between boys and girls and between 11- to 14-year-olds and 15- to 20-year-olds. Correlations between substance use and meeting individual movement recommendations were examined using a combination of pairwise Pearson's and Spearman correlations. The strength of the correlation coefficients was categorized as follows: weak (less than 0.4 ), moderate (0.4 to 0.7), and strong (more than 0.7) [46]. Subsequent analyses were conducted in boys and girls separately, because a two-way interaction between gender and movement behaviors was statistically significant $(p<0.05)$ for all outcomes. However, for cannabis use only, a two-way interaction between age and movement behaviors was significant, but not three-way interaction between gender, age, and movement behaviors; thus, analyses for cannabis use were also stratified by age groups. Meeting individual guideline recommendations was binary coded as 0 (not meeting the guideline) or 1 (meeting the guideline). A new variable was constructed to represent different combinations of the three guideline recommendations, thus generating eight categories (i.e., meeting none, meeting the physical activity recommendation only, meeting the screen time recommenda- 
tion only, meeting the sleep duration recommendation only, meeting the physical activity and screen time recommendations only, meeting the physical activity and sleep duration recommendations only, meeting the screen time and sleep duration recommendations only, meeting all three recommendations) where meeting none of the guidelines was treated as the reference category.

The association between meeting individual and different combinations of movement behavior guidelines (independent variables) and substance use outcomes of alcohol consumption, tobacco smoking, and cannabis use (dependent variables) were examined using logistic regression analyses. The regression models controlled for ethnicity, gender, BMI $z$-score, and subjective SES as potential confounders. A total of 10,236 participants out of 11,435 were retained for our analyses, because they had complete information on all variables of interest. Compared to included participant, those who were excluded (due to missing data) were more likely to be aged 11-to-14-years ( $58.6 \%$ vs. $37.7 \%$ ), less likely to be of a White ethnicity ( $48.0 \%$ vs. $56.2 \%)$, had higher BMI $z$-scores, and were more likely to meet the sleep duration recommendation ( $44.8 \%$ vs. $33.8 \%$ ) (Table S1). Given that the OSDUHS uses a two-stage (school, class) stratified (region and school type) cluster sample design, all analyses were adjusted for this complex sample design using Taylor series linearization methods in Stata 16.0 (Stata Corporation, College Station, TX, USA).

\section{Results}

Table 1 outlines descriptive characteristics of the sample. Just over two-thirds were 15-to-20-year-olds, almost one-half were girls, and 56.3\% identified themselves as White. Overall, 39\% met none of the recommendations, $7.7 \%$ met the physical activity recommendation only, $13.8 \%$ met the screen time recommendation only, and $15.4 \%$ met the sleep duration recommendation only. Only $5 \%$ of participants met all three recommendations. The proportion of boys and girls meeting the sleep duration recommendation only was not significantly different $(p=0.093)$. Boys were more likely than girls to meet the physical activity recommendation only $(p<0.001)$, whereas girls were more likely than boys to meet the screen time recommendation only $(p<0.001)$. Boys were more likely than girls to meet all three recommendations $(p<0.001)$. Boys were also more likely than girls to report smoking tobacco cigarette $(p=0.037)$. The prevalence of adherence to the screen time, sleep duration, and physical activity recommendations was greater for 11 to 14-year-olds than for 15-to-20-year-old counterparts $(p<0.001)$. Conversely, 15-to-20-year-olds were more likely than 11-to-14-year-olds to report smoking tobacco cigarette, consuming alcohol, and using cannabis $(p<0.001)$ (Table 1$)$.

Correlation coefficients among substance use and meeting individual guideline recommendations are presented in Table 2. Alcohol consumption and cigarette smoking were moderately associated with cannabis use. Overall, the correlation between 24-h movement guidelines and substance use were statistically significant but weak. Adherence to the physical activity recommendation was positively associated with adherence to the sleep duration and screen time recommendations. Conversely, it was negatively associated with alcohol consumption, cannabis use, and cigarette smoking. Adherence to the screen time recommendation was positively associated with adherence to the sleep duration recommendation. However, it was negatively associated with alcohol consumption and cannabis use. Adherence to the sleep duration recommendation was negatively associated with smoking tobacco cigarette, alcohol consumption, and cannabis use. 
Table 1. Descriptive characteristics of the study sample.

\begin{tabular}{|c|c|c|c|c|c|c|c|}
\hline Characteristics & $\begin{array}{c}\text { Total Sample } \\
(n=10,236)\end{array}$ & $\begin{array}{c}\text { Boys } \\
(n=4431)\end{array}$ & $\begin{array}{c}\text { Girls } \\
(n=5805)\end{array}$ & $p$ Value & $\begin{array}{l}\text { 11-to-14-Year-Olds } \\
\quad(n=4871)\end{array}$ & $\begin{array}{l}\text { 15-to-20-Year-Olds } \\
\quad(n=5365)\end{array}$ & $p$ Value \\
\hline \multicolumn{8}{|l|}{ Age (years) } \\
\hline Mean (SD) & $15.1(1.8)$ & $15.2(1.7)$ & $15.1(1.9)$ & & $13.2(0.9)$ & $16.3(0.9)$ & \\
\hline 11-to-14-year-olds & 37.7 & 37.1 & 38.3 & 0.515 & & & \\
\hline 15-to-20-year-olds & 62.3 & 62.9 & 61.7 & & & & \\
\hline \multicolumn{8}{|l|}{ Gender } \\
\hline Boys & 51.1 & & & & 49.6 & 48.4 & 0.515 \\
\hline Girls & 48.8 & & & & 50.4 & 51.6 & \\
\hline \multicolumn{8}{|l|}{ Ethnic background } \\
\hline White & 56.3 & 58.6 & 54.0 & 0.210 & 54.9 & 57.2 & 0.367 \\
\hline Black & 9.8 & 9.5 & 10.1 & & 9.3 & 10.1 & \\
\hline East/South-East Asian & 8.8 & 8.4 & 9.2 & & 8.3 & 9.1 & \\
\hline South Asian & 7.1 & 7.2 & 6.9 & & 8.5 & 6.2 & \\
\hline Other & 18.0 & 16.3 & 19.8 & & 18.9 & 17.5 & \\
\hline \multicolumn{8}{|l|}{$\begin{array}{l}\text { Subjective socioeconomic } \\
\text { status }\end{array}$} \\
\hline Mean (SD) & $6.9(1.7)$ & $7.0(1.6)$ & $6.9(1.8)$ & 0.556 & $7.1(1.8)$ & $6.8(1.6)$ & $<0.001$ \\
\hline \multicolumn{8}{|l|}{ Body mass index $z$-score } \\
\hline Mean (SD) & $0.3(1.1)$ & $0.3(1.0)$ & $0.3(1.3)$ & 0.555 & $0.3(1.3)$ & $0.4(1.0)$ & 0.003 \\
\hline \multicolumn{8}{|l|}{$\begin{array}{l}\text { Combination of meeting } \\
\text { movement guideline } \\
\text { recommendations }\end{array}$} \\
\hline Meeting none & 39.0 & 34.0 & 44.2 & $<0.001$ & 30.5 & 44.2 & $<0.001$ \\
\hline PA only & 7.7 & 9.7 & 5.6 & & 9.7 & 6.5 & \\
\hline ST only & 13.8 & 11.5 & 16.2 & & 12.1 & 14.8 & \\
\hline Sleep only & 15.4 & 16.4 & 14.3 & & 14.8 & 15.7 & \\
\hline PA and ST only & 5.9 & 7.5 & 4.4 & & 8.0 & 4.7 & \\
\hline PA and sleep only & 4.6 & 6.0 & 3.1 & & 6.5 & 3.4 & \\
\hline ST and sleep only & 8.6 & 7.6 & 9.6 & & 11.4 & 6.9 & \\
\hline Meeting all 3 & 5.1 & 7.4 & 2.7 & & 7.0 & 4.0 & \\
\hline \multicolumn{8}{|l|}{ Cigarette smoking } \\
\hline No & 92.6 & 91.3 & 93.9 & 0.037 & 98.7 & 88.9 & $<0.001$ \\
\hline Yes & 7.4 & 8.7 & 6.1 & & 1.3 & 11.1 & \\
\hline \multicolumn{8}{|l|}{ Alcohol consumption } \\
\hline No & 55.6 & 55.1 & 56.0 & 0.696 & 81.1 & 40.1 & $<0.001$ \\
\hline Yes & 44.4 & 44.9 & 44.0 & & 18.9 & 59.9 & \\
\hline \multicolumn{8}{|l|}{ Cannabis use } \\
\hline No & 77.7 & 77.2 & 78.2 & 0.442 & 94.8 & 67.3 & $<0.001$ \\
\hline Yes & 22.3 & 22.8 & 21.8 & & 5.2 & 32.7 & \\
\hline
\end{tabular}

Data are shown as column \%, unless otherwise indicated. SD: standard deviation.

Table 2. Spearman's correlation coefficients among meeting individual guideline recommendations and substance use among adolescents.

\begin{tabular}{|c|c|c|c|c|c|c|}
\hline & Physical Activity & Screen Time & Sleep & Smoking & Alcohol & Cannabis \\
\hline Physical activity & 1 & & & & & \\
\hline Screen time & $0.14^{* * *}$ & 1 & & & & \\
\hline Sleep & $0.10^{* * *}$ & $0.13^{* * *}$ & 1 & & & \\
\hline Smoking & $-0.03^{* * *}$ & 0.00 & $-0.05^{* * *}$ & 1 & & \\
\hline Alcohol & $-0.04^{* * *}$ & $-0.03 * * *$ & $-0.11^{* * *}$ & $0.29^{* * *}$ & 1 & \\
\hline Cannabis & $-0.05^{* * *}$ & $-0.04^{* * *}$ & $-0.09^{* * *}$ & $0.45^{* * *}$ & $0.51^{* * *}$ & 1 \\
\hline
\end{tabular}


As shown in Table 3, after adjusting for important covariates, results from logistic regression analyses showed that among boys, adherence to the physical activity recommendation only was associated with lower odds of smoking tobacco cigarette (OR $=0.31 ; 95 \%$ CI: 0.14-0.68), adherence to the sleep duration recommendation only was associated with lower odds of alcohol consumption (OR $=0.47 ; 95 \% \mathrm{CI}$ : 0.31-0.72), and meeting both the physical activity and screen time recommendations was associated with a lower odds of cannabis use (OR $=0.55 ; 95 \%$ CI: $0.32-0.96)$. Surprisingly, meeting both the physical activity and screen time recommendations was associated with greater odds of alcohol consumption $(\mathrm{OR}=1.54 ; 95 \% \mathrm{CI}: 1.05-2.25)$. Among girls, meeting all three recommendations was associated with lower odds of cannabis use ( $\mathrm{OR}=0.35$; $95 \% \mathrm{CI}$ : $0.17-0.72)$; adherence to the physical activity and sleep duration recommendations only was associated with lower odds of smoking tobacco cigarette ( $\mathrm{OR}=0.02 ; 95 \% \mathrm{CI}$ : $0.00-0.18)$. Adherence to the screen time recommendation only ( $\mathrm{OR}=0.68 ; 95 \% \mathrm{CI}$ : $0.48-0.96)$, sleep duration only $(\mathrm{OR}=0.53$; 95\% CI: 0.36-0.78), or both screen time and sleep duration (OR $=0.32$; $95 \%$ CI: $0.22-0.47$ ) recommendations was associated with lower odds of alcohol consumption. Adherence to the physical activity recommendation only was associated with lower odds of cannabis use $(\mathrm{OR}=0.68$; 95\% CI: 0.47-0.99).

Table 3. Association between different combinations of movement behavior recommendations and substance use by gender.

\begin{tabular}{|c|c|c|c|c|c|c|}
\hline & \multicolumn{2}{|c|}{ Cigarette Smoking } & \multicolumn{2}{|c|}{ Alcohol Consumption } & \multicolumn{2}{|c|}{ Cannabis Use } \\
\hline & $\begin{array}{c}\text { Boys } \\
(n=4431)\end{array}$ & $\begin{array}{c}\text { Girls } \\
(n=5805)\end{array}$ & $\begin{array}{c}\text { Boys } \\
(n=4431)\end{array}$ & $\begin{array}{c}\text { Girls } \\
(n=5805)\end{array}$ & $\begin{array}{c}\text { Boys } \\
(n=4431)\end{array}$ & $\begin{array}{c}\text { Girls } \\
(n=5805)\end{array}$ \\
\hline & OR $(95 \% \mathrm{CI})$ & OR $(95 \% \mathrm{CI})$ & OR $(95 \%$ CI $)$ & OR $(95 \%$ CI $)$ & OR $(95 \% \mathrm{CI})$ & OR $(95 \% \mathrm{CI})$ \\
\hline \multicolumn{7}{|l|}{ Unadjusted } \\
\hline Meeting none & 1 & 1 & 1 & 1 & 1 & 1 \\
\hline PA only & $0.28(0.13-0.60)$ & $0.84(0.43-1.64)$ & $0.75(0.47-1.20)$ & $0.81(0.58-1.13)$ & $0.87(0.59-1.28)$ & $0.68(0.48-0.98)$ \\
\hline ST only & $0.62(0.35-1.10)$ & $1.05(0.61-1.81)$ & $0.88(0.61-1.27)$ & $0.84(0.60-1.16)$ & $0.83(0.57-1.22)$ & $0.82(0.60-1.14)$ \\
\hline Sleep only & $0.83(0.46-1.49)$ & $0.78(0.34-1.77)$ & $0.61(0.40-0.93)$ & $0.68(0.51-0.92)$ & $0.60(0.35-1.03)$ & $0.84(0.63-1.12)$ \\
\hline PA and ST only & $0.39(0.19-0.80)$ & $0.40(0.18-0.92)$ & $1.08(0.79-1.48)$ & $1.16(0.74-1.82)$ & $0.56(0.34-0.93)$ & $0.79(0.33-1.88)$ \\
\hline PA and sleep only & $0.45(0.19-1.05)$ & $0.02(0.03-0.16)$ & $0.47(0.30-0.75)$ & $0.63(0.31-1.32)$ & $0.56(0.33-0.95)$ & $0.42(0.14-1.21)$ \\
\hline ST and sleep only & $0.62(0.25-1.55)$ & $0.49(0.25-0.94)$ & $0.78(0.49-1.24)$ & $0.32(0.22-0.47)$ & $0.71(0.42-1.18)$ & $0.51(0.19-1.33)$ \\
\hline Meeting all 3 & $0.92(0.36-2.36)$ & $0.31(0.07-1.42)$ & $0.68(0.45-1.03)$ & $0.43(0.24-0.79)$ & $0.60(0.33-1.08)$ & $0.36(0.18-0.75)$ \\
\hline \multicolumn{7}{|l|}{ Adjusted } \\
\hline Meeting none & 1 & 1 & 1 & 1 & 1 & 1 \\
\hline PA only & $0.31(0.14-0.68)$ & $1.19(0.58-2.48)$ & $0.96(0.51-1.78)$ & $1.37(0.94-1.99)$ & $0.86(0.59-1.27)$ & $0.68(0.47-0.99)$ \\
\hline ST only & $0.71(0.40-1.26)$ & $0.92(0.54-1.57)$ & $0.95(0.55-1.65)$ & $0.68(0.48-0.96)$ & $0.88(0.60-1.31)$ & $0.79(0.57-1.08)$ \\
\hline Sleep only & $0.72(0.41-1.28)$ & $0.62(0.27-1.46)$ & $0.47(0.31-0.72)$ & $0.53(0.36-0.78)$ & $0.61(0.37-1.01)$ & $0.79(0.60-1.05)$ \\
\hline PA and ST only & $0.49(0.21-1.15)$ & $0.51(0.22-1.16)$ & $1.54(1.05-2.25)$ & $1.46(0.91-2.35)$ & $0.55(0.32-0.96)$ & $0.73(0.29-1.85)$ \\
\hline PA and sleep only & $0.80(0.30-2.17)$ & $0.02(0.00-0.18)$ & $0.70(0.42-1.18)$ & $0.76(0.32-1.82)$ & $0.66(0.38-1.14)$ & $0.38(0.13-1.17)$ \\
\hline ST and sleep only & $0.73(0.30-1.77)$ & $0.59(0.31-1.10)$ & $0.91(0.42-1.18)$ & $0.32(0.22-0.47)$ & $0.75(0.46-1.22)$ & 0.49 (0.19-1.30) \\
\hline Meeting all 3 & $1.48(0.63-3.46)$ & $0.41(0.08-2.09)$ & $0.82(0.60-1.38)$ & $0.62(0.35-1.08)$ & 0.67 (0.39-1.13) & $0.35(0.17-0.72)$ \\
\hline
\end{tabular}

OR: odds ratio; CI: confidence interval; PA: physical activity; ST: screen time. Models are adjusted for ethnicity, gender, body mass index $z$-score, and subjective socioeconomic status.

As shown in Table 4, adherence to the sleep duration recommendation only ( $\mathrm{OR}=0.48$; $95 \%$ CI: $0.27-0.85$ ) or the screen time and sleep duration recommendations only (OR $=0.35$; 95\% CI: 0.13-0.91) were associated with lower odds of cannabis use among 11- to-14-yearolds, but not among 15-to-20-year-olds. 
Table 4. Association between different combinations of movement behavior recommendations and cannabis use by age group.

\begin{tabular}{|c|c|c|}
\hline & $\begin{array}{c}\text { 11-to-14-Year-Olds } \\
(n=4871)\end{array}$ & $\begin{array}{c}\text { 15-to-20-Year-Olds } \\
(n=5365)\end{array}$ \\
\hline & OR (95\% CI) & OR $(95 \% \mathrm{CI})$ \\
\hline \multicolumn{3}{|l|}{ Unadjusted } \\
\hline Meeting none & 1 & 1 \\
\hline PA only & $0.99(0.57-1.73)$ & $1.10(0.73-1.66)$ \\
\hline ST only & $0.61(0.29-1.29)$ & $0.89(0.65-1.24)$ \\
\hline Sleep only & $0.46(0.26-0.83)$ & $0.81(0.54-1.22)$ \\
\hline PA and ST only & $0.72(0.38-1.35)$ & $0.94(0.60-1.46)$ \\
\hline PA and sleep only & $0.66(0.27-1.60)$ & $0.77(0.43-1.38)$ \\
\hline ST and sleep only & $0.34(0.13-0.90)$ & $0.93(0.51-1.72)$ \\
\hline Meeting all 3 & $0.34(0.12-0.95)$ & $0.88(0.46-1.67)$ \\
\hline \multicolumn{3}{|l|}{ Adjusted } \\
\hline Meeting none & 1 & 1 \\
\hline PA only & $1.02(0.58-1.78)$ & $1.07(0.71-1.61)$ \\
\hline ST only & $0.62(0.30-1.30)$ & $0.89(0.65-1.20)$ \\
\hline Sleep only & $0.48(0.27-0.85)$ & $0.78(0.52-1.15)$ \\
\hline PA and ST only & $0.70(0.37-1.35)$ & $0.88(0.53-1.47)$ \\
\hline PA and sleep only & $0.69(0.30-1.57)$ & $0.78(0.46-1.34)$ \\
\hline ST and sleep only & $0.35(0.13-0.91)$ & $0.94(0.50-1.77)$ \\
\hline Meeting all 3 & $0.37(0.12-1.09)$ & $0.85(0.47-1.55)$ \\
\hline
\end{tabular}

OR: odds ratio; CI: confidence interval; PA: physical activity; ST: screen time. Models are adjusted for ethnicity, gender, body mass index $z$-score, and subjective socioeconomic status.

Results of sensitivity analyses using more severe levels of substance use as the exposure are outlined in Tables S2 and S3. Overall, they showed similar patterns of association, but with some exceptions and very wide confidence intervals.

\section{Discussion}

This is the first study to examine the association between all possible combinations of screen time, sleep duration, and physical activity with substance use among adolescents. Past research has mainly focused on investigating the associations between a single recommendation of the guidelines and substance use among adolescents [15-21,32], ignoring how these behaviors may concurrently relate to substance use among adolescents. We observed that different combinations of the guideline recommendations were associated with all substance use differentially between type of recommendation met, type of substance use, and gender, as well as age for cannabis use. Contrary to our hypothesis that adherence to the Canadian 24-h movement guidelines would be associated with reduced substance use among adolescents, particularly among boys and younger adolescents as they are more likely than girls to meet all three recommendations, we observed that meeting all three guideline recommendations was associated with lower odds of cannabis use in girls only. These findings are somewhat surprising because meeting all 3 guideline recommendations should be strongly (lower odds) associated with all the outcomes, and behaviors tend to cluster within individuals. Our analyses may be underpowered to detect small and, in some cases, moderate differences. Future studies with more statistical power are needed to replicate our analyses. 
Meeting movement behavior guidelines has been associated with improved indicators of physical, mental, and social health, such as less impulsivity, better self-regulation, cognition, and decision-making, higher social connectedness, and better psychosocial functioning [25,47]. All these outcomes have been indicated to protect adolescents from engaging in risky behaviors such as substance use $[48,49]$. It is also possible that adolescents who do not use substances have a better self-regulation, and therefore could be more likely to value and lead a healthy lifestyle and meet the guidelines. Regardless, research has shown that unhealthy behaviors (e.g., lack of physical activity, smoking, alcohol, unhealthy eating, etc.) tend to cluster together within individuals [35-38]. As such, from an intervention standpoint, reducing substance use among adolescents should be integrated within broader health-promoting initiatives.

Our results showed that adherence to the physical activity recommendation was associated with lower odds of smoking tobacco cigarette and cannabis use among boys. Whereas among girls, meeting both the physical activity and sleep duration recommendations was associated with lower odds of smoking tobacco cigarette; and, adherence to the physical activity recommendation only or all three recommendations were associated with lower odds of cannabis use. Our results are in line with previous research suggesting that physical activity may protect adolescents from smoking and cannabis use [50,51]. In a prospective cohort study of over 1300 US adolescents aged 14 to 18 years, AudrainMcGovern and Rodriguez [52] found that the influence of physical activity on the uptake of cigarette smoking largely depends on the types of physical activity youth engage in. They found that physical activity types that are associated with lower odds of smoking include racquet sports, running, and swimming laps, whereas skating, walking, bicycling, sport fighting, and competitive wrestling are positively associated with smoking [52]. In a sample of over 6800 Norwegian adolescents aged 13-19 years, Holmen et al. [53] found that participating in sports that involve lesser endurance, such as fighting sports or body-building was related to daily smoking cigarettes. Findings from the present study do not discriminate types of physical activity, but support that getting $60 \mathrm{~min}$ of daily physical activity at moderate to vigorous intensity (MVPA) was associated with lower odds of tobacco and cannabis use, but further research into intensity, duration and type of physical activity is needed. However, the finding that physical activity was not negatively associated with smoking and cannabis use when it was paired with adherence to the sleep duration recommendation among boys suggests that sufficient sleep duration could explain this relationship. Future research formally testing the mediating role of sufficient sleep on the relationship between physical activity and substance use is needed.

Adherence to the sleep duration recommendation only was associated with lower odds of alcohol consumption among boys. However, adherence to the sleep duration recommendation only, screen time recommendation only, or both was associated with lower odds of alcohol consumption among girls. These findings identify sleep duration as an important correlate of alcohol consumption and are somewhat consistent with previous studies that have found that short sleep duration is associated with the age of onset and total alcohol consumption among adolescents $[20,21,54]$ and adults [55]. Studies have also shown that screen time is associated with greater risk of alcohol consumption and binge drinking among adolescents $[18,56]$. It is possible that higher screen use increases exposure to alcohol advertising, which in turn may result in more positive beliefs about drinking and desire for alcohol initiation, which are predictive of underage drinking [56-62]. The observed gender differences in the associations between combinations of movement guidelines and alcohol consumption are interesting and deserve more investigation. It is well-known that adult men are more likely than women to consume alcohol $[63,64]$; however, current literature is inconsistent for such differences in adolescents $[65,66]$, indicating the gender differences in association with movement behaviors are not simply a reflection of higher alcohol use in one gender over another. Research indicated that gender differences in alcohol use become more apparent around the age of 18 [67]. 
Surprisingly, meeting both the physical activity and screen time recommendations was associated with greater odds of alcohol consumption. These findings are contrary to our hypothesis that adherence to the 24-h movement guidelines would be negatively associated with substance use among adolescents and deserve further investigation. There is compelling evidence that physical activity, particularly competitive sport, is positively associated with current and future alcohol use among adolescents and young adults $[15,68]$. Research has also suggested that adolescents who play sports intensively drink more than those who practice sports in moderation [69], and those who participated in group sports drink more than those who participated as individuals [70,71]. However, our survey did not ask about specific activities youth engage in while exercising nor the intensity of such activities. Future research is needed to examine how different types and intensities of physical activity relate to alcohol consumption among adolescents.

Our results showed that meeting both the physical activity and screen time recommendations was associated with lower odds of cannabis use among boys. Whereas among girls, adherence to the physical activity recommendation only or all three recommendations was associated with lower odds of cannabis use. Our results are somewhat consistent with previous studies indicating a negative association between physical activity and cannabis use [15]. For example, Wichstrøm and Wichstrøm [71] found that participation in team sports and endurance sports may reduce later cannabis use. Furthermore, physical activity has also been identified as an adjunctive treatment for cannabis use disorder [72]. Our results suggest that adherence to the 24 -h movement guidelines, particularly the physical activity component, may play an important role in the prevention of cannabis use among adolescents. Contrary to Knell et al. [23] who found that meeting all three recommendations was associated with lower odds of cannabis use among boys, the present study documented such an association among girls, but not boys. The observed difference may be explained at least in part by the older age of the US sample (high school students), whereas our study included both middle and high school students.

Results further indicated that adherence to the sleep duration recommendation only or both the sleep duration and screen time recommendations was associated with lower odds of cannabis use among 11- to 14-year-olds but not among 15- to 20-year-olds. Our results are consistent with previous studies that have identified sleep duration as an important correlate of cannabis use among adolescents. For example, in a prospective study of over 800 US adolescents aged 12 to 16 years, Miller et al. [21] found that short sleep duration was associated with increased odds of cannabis use. These findings suggest that compliance to the sleep duration and screen time recommendations have added benefits to protect against cannabis use than compliance to the physical activity recommendation among younger adolescents. Excessive screen time is very common among adolescents [73,74], and it is associated with short sleep duration in this age group $[75,76]$. Replication studies using a longitudinal design are needed to confirm if adherence to the sleep duration and screen time recommendations could help spare younger adolescents from engaging in cannabis use.

\section{Strengths and Limitations}

Strengths of this study include: (1) The fact that it was based on a large and representative sample of the Ontario school population; (2) an assessment of multiple substance use outcomes, specifically alcohol consumption, cannabis use, and cigarette smoking; (3) a focus on adherence to different combinations of movement behavior recommendations, as previous studies have been limited to adherence to individual recommendations; and (4) the inclusion of a comprehensive set of covariates that statistically controlled for important confounding variables, strengthening the internal validity of the findings. Some limitations of the study should be noted. First, the cross-sectional nature of the data precludes temporality and inference of causality between adherence to the 24-h movement guidelines and substance use. Second, physical activity, screen time, sleep duration, and substance use were based on self-reports, and may be subject to recall or desirability biases. Third, 
the present study did not measure types of physical activity nor screen time. Research has shown that different types/intensities of physical activity and different types of screen time could be differentially associated with substance use in children and adolescents $[77,78]$. Fourth, the use of single item measures of alcohol consumption, cannabis use, and cigarette smoking may raise reliability issues. Finally, the survey was restricted to adolescent students enrolled in publicly funded schools, thus excluding by design out-of-scope groups for which substance use is elevated, such as institutionalized youths, truant youth, and homeless/street youth.

\section{Conclusions}

Findings from this study suggest that adherence to the 24-h movement behavior recommendations is differentially associated with lower odds of alcohol consumption, cannabis use, and cigarette smoking among adolescent boys and girls. Overall, meeting all of the 24-h movement behavior guidelines was not associated with substance use in boys, and even in girls, only less cannabis use was. Rather, certain individual or combinations of guidelines were more associated with substance use in boys and girls. No gradient or dose response was documented in our data. More specifically, our study identifies physical activity as an important correlate of reduced cigarette smoking, short sleep duration as an important correlate of alcohol consumption, and both physical activity and sleep duration as important correlates of lower cannabis use among adolescents. Replications studies using a larger sample size, objective measures of 24-h movement behaviors, and prospective data are needed to confirm our findings, explain the observed differences across gender and age, and examine if encouraging students to meet the 24-h movement guidelines could protect against substance use.

Supplementary Materials: The following are available online at https:/ /www.mdpi.com/1660-460 1/18/6/3309/s1. Table S1. Descriptive characteristics of participants who were included vs. those who were excluded from our analyses, Table S2. Results of sensitivity analyses testing the link between different combinations of compliance to the movement behavior recommendations and substance use by gender, Table S3. Results of sensitivity analyses testing the association between combinations of adherence to movement behavior recommendations and cannabis use by age group.

Author Contributions: Conceptualization, H.S.-K., I.C., G.S.G., I.J., J.W., H.A.H., and J.-P.C.; methodology, H.S.-K., I.C., G.S.G., I.J., J.W., H.A.H., and J.-P.C.; software, I.C.; formal analysis, H.S.-K.; data curation, H.A.H.; writing-original draft preparation, H.S.-K.; writing-review and editing, I.C., G.S.G., I.J., J.W., H.A.H., and J.-P.C.; supervision, I.C. and J.-P.C.; funding acquisition, I.C. and J.-P.C. All authors have read and agreed to the published version of the manuscript.

Funding: This research was partly founded by the Research Council of Norway through its Centres of Excellence funding scheme, project number 262700 for Ian Colman. Ian Colman and Ian Janssen are funded by Canada Research Chair awards.

Institutional Review Board Statement: The study was conducted according to the guidelines of the Declaration of Helsinki, and approved by the Research Ethics Boards at the Centre for Addiction and Mental Health (029/2016) and York University (e2014-099), as well as 31 school board research review committees.

Informed Consent Statement: Informed consent was obtained from all subjects involved in the study.

Data Availability Statement: Our data cannot be made available in the manuscript, the supplemental files or a public repositor due to the Centre for Addiction and Mental Health's and The Ontario Public and Catholic School Board's institutional Research Ethics Board agreements y. Readers, however, may contact to request the public data file underlying the findings of this study by contacting the Centre for Addiction and Mental Health at info@camh.ca

Conflicts of Interest: The authors declare no conflict of interest. 


\section{References}

1. Schulte, M.T.; Hser, Y.-I. Substance Use and Associated Health Conditions throughout the Lifespan. Public Health Rev. 2014, 35. [CrossRef] [PubMed]

2. World Health Organization. WHO Report on the Global Tobacco Epidemic, 2008: The MPOWER Package; World Health Organization: Geneva, Switzerland, 2008.

3. Nazir, M.A.; Al-Ansari, A.; Abbasi, N.; Almas, K. Global Prevalence of Tobacco Use in Adolescents and Its Adverse Oral Health Consequences. Open Access Maced. J. Med. Sci. 2019, 7, 3659-3666. [CrossRef]

4. Boak, A.; Hamilton, H.A.; Adlaf, E.M.; Mann, R.E. Drug Use among Ontario Students, 1977-2017: Detailed Findings from the Ontario Student Drug Use and Health Survey (OSDUHS) (CAMH Research Document Series No. 46); Centre for Addiction and Mental Health: Toronto, ON, Canada, 2017.

5. Rehm, J.; Shield, K.D.; Joharchi, N.; Shuper, P.A. Alcohol consumption and the intention to engage in unprotected sex: Systematic review and meta-analysis of experimental studies. Addiction 2012, 107, 51-59. [CrossRef] [PubMed]

6. Hingson, R.W.; Heeren, T.; Jamanka, A.; Howland, J. Age of Drinking Onset and Unintentional Injury Involvement after Drinking. JAMA 2000, 284, 1527-1533. [CrossRef]

7. Health Canada. Canadian Student Tobacco, Alcohol and Drugs Survey-2016-2017 Supplementary Tables; Health Canada: Ottawa, ON, Canada, 2018.

8. Shapiro, G.K.; Buckley-Hunter, L. What every adolescent needs to know: Cannabis can cause psychosis. J. Psychosom. Res. 2010, 69, 533-539. [CrossRef] [PubMed]

9. Roffman, R. Legalization of cannabis in Washington State: How is it going? Addiction 2016, 111, 1139-1140. [CrossRef] [PubMed]

10. Boak, A.; Elton-Marshall, T.; Mann, R.E.; Hamilton, H.A. Drug Use among Ontario Students, 1977-2019: Detailed Findings from the Ontario Student Drug Use and Health Survey (OSDUHS); Centre for Addiction and Mental Health: Toronto, ON, Canada, 2020.

11. Poitras, V.J.; Gray, C.E.; Borghese, M.M.; Carson, V.; Chaput, J.-P.; Janssen, I.; Katzmarzyk, P.T.; Pate, R.R.; Connor Gorber, S.; Kho, M.E. Systematic review of the relationships between objectively measured physical activity and health indicators in school-aged children and youth. Appl. Physiol. Nutr. Metab. 2016, 41, S197-S239. [CrossRef]

12. Tremblay, M.S.; LeBlanc, A.G.; Kho, M.E.; Saunders, T.J.; Larouche, R.; Colley, R.C.; Goldfield, G.; Connor Gorber, S. Systematic review of sedentary behaviour and health indicators in school-aged children and youth. Int. J. Behav. Nutr. Phys. Act. 2011, 8, 98. [CrossRef]

13. Chaput, J.-P.; Gray, C.E.; Poitras, V.J.; Carson, V.; Gruber, R.; Olds, T.; Weiss, S.K.; Connor Gorber, S.; Kho, M.E.; Sampson, M. Systematic review of the relationships between sleep duration and health indicators in school-aged children and youth. Appl. Physiol. Nutr. Metab. 2016, 41, S266-S282. [CrossRef]

14. Hirshkowitz, M.; Whiton, K.; Albert, S.M.; Alessi, C.; Bruni, O.; DonCarlos, L.; Hazen, N.; Herman, J.; Katz, E.S.; KheirandishGozal, L.; et al. National Sleep Foundation's sleep time duration recommendations: Methodology and results summary. Sleep Health 2015, 1, 40-43. [CrossRef]

15. Brellenthin, A.G.; Lee, D. Physical Activity and the Development of Substance Use Disorders: Current Knowledge and Future Directions. Prog. Prev. Med. (N. Y.) 2018, 3, e0018. [CrossRef] [PubMed]

16. Brown, J.D.; Witherspoon, E.M. The mass media and American adolescents' health. J. Adolesc. Health 2002, 31, 153-170. [CrossRef]

17. Ströhle, A.; Hoefler, M.; Pfister, H.; Mueller, A.-G.; Hoyer, J.; Wittchen, H.-U.; Lieb, R. Physical activity and prevalence and incidence of mental disorders in adolescents and young adults. Psychol. Med. 2007, 37, 1657-1666. [CrossRef]

18. Sampasa-Kanyinga, H.; Chaput, J.P. Use of social networking sites and alcohol consumption among adolescents. Public Health 2016, 139, 88-95. [CrossRef]

19. Sampasa-Kanyinga, H.; Hamilton, H.A. Use of social networking sites, electronic cigarettes, and waterpipes among adolescents. Public Health 2018, 164, 99-106. [CrossRef] [PubMed]

20. Pasch, K.E.; Latimer, L.A.; Cance, J.D.; Moe, S.G.; Lytle, L.A. Longitudinal bi-directional relationships between sleep and youth substance use. J. Youth Adolesc. 2012, 41, 1184-1196. [CrossRef] [PubMed]

21. Miller, M.B.; Janssen, T.; Jackson, K.M. The Prospective Association Between Sleep and Initiation of Substance Use in Young Adolescents. J. Adolesc. Health 2017, 60, 154-160. [CrossRef]

22. Tremblay, M.S.; Carson, V.; Chaput, J.P.; Connor Gorber, S.; Dinh, T.; Duggan, M.; Faulkner, G.; Gray, C.E.; Gruber, R.; Janson, K.; et al. Canadian 24-h Movement Guidelines for Children and Youth: An Integration of Physical Activity, Sedentary Behaviour, and Sleep. Appl. Physiol. Nutr. Metab. 2016, 41, S311-S327. [CrossRef] [PubMed]

23. Knell, G.; Durand, C.P.; Kohl, H.W., 3rd; Wu, I.H.C.; Pettee Gabriel, K. Prevalence and Likelihood of Meeting Sleep, Physical Activity, and Screen-Time Guidelines Among US Youth. JAMA Pediatr. 2019, 173, 387-389. [CrossRef]

24. Pearson, N.; Sherar, L.B.; Hamer, M. Prevalence and Correlates of Meeting Sleep, Screen-Time, and Physical Activity Guidelines Among Adolescents in the United Kingdom. JAMA Pediatr. 2019, 173, 993-994. [CrossRef]

25. Walsh, J.J.; Barnes, J.D.; Cameron, J.D.; Goldfield, G.S.; Chaput, J.P.; Gunnell, K.E.; Ledoux, A.A.; Zemek, R.L.; Tremblay, M.S. Associations between $24 \mathrm{~h}$ movement behaviours and global cognition in US children: A cross-sectional observational study. Lancet Child Adolesc. Health 2018, 2, 783-791. [CrossRef]

26. Janssen, I.; Roberts, K.C.; Thompson, W. Adherence to the 24-h Movement Guidelines among 10- to 17-year-old Canadians. Health Promot. Chronic Dis. Prev. Can. 2017, 37, 369-375. [CrossRef] 
27. Roman-Vinas, B.; Chaput, J.P.; Katzmarzyk, P.T.; Fogelholm, M.; Lambert, E.V.; Maher, C.; Maia, J.; Olds, T.; Onywera, V.; Sarmiento, O.L.; et al. Proportion of children meeting recommendations for 24-h movement guidelines and associations with adiposity in a 12-country study. Int. J. Behav. Nutr. Phys. Act. 2016, 13, 123. [CrossRef] [PubMed]

28. Roberts, K.C.; Yao, X.; Carson, V.; Chaput, J.P.; Janssen, I.; Tremblay, M.S. Meeting the Canadian 24-h Movement Guidelines for Children and Youth. Health Rep. 2017, 28, 3-7.

29. Guerrero, M.D.; Barnes, J.D.; Walsh, J.J.; Chaput, J.P.; Tremblay, M.S.; Goldfield, G.S. 24-h Movement Behaviors and Impulsivity. Pediatrics 2019, 144. [CrossRef]

30. Thivel, D.; Tremblay, M.S.; Katzmarzyk, P.T.; Fogelholm, M.; Hu, G.; Maher, C.; Maia, J.; Olds, T.; Sarmiento, O.L.; Standage, M.; et al. Associations between meeting combinations of 24-h movement recommendations and dietary patterns of children: A 12-country study. Prev. Med. 2019, 118, 159-165. [CrossRef] [PubMed]

31. Sampasa-Kanyinga, H.; Standage, M.; Tremblay, M.S.; Katzmarzyk, P.T.; Hu, G.; Kuriyan, R.; Maher, C.; Maia, J.; Olds, T.; Sarmiento, O.L.; et al. Associations between meeting combinations of 24-h movement guidelines and health-related quality of life in children from 12 countries. Public Health 2017, 153, 16-24. [CrossRef] [PubMed]

32. Peretti-Watel, P.; Beck, F.; Legleye, S. Beyond the U-curve: The relationship between sport and alcohol, cigarette and cannabis use in adolescents. Addiction 2002, 97, 707-716. [CrossRef] [PubMed]

33. Johnston, L.D.; Miech, R.A.; O’Malley, P.M.; Bachman, J.G.; Schulenberg, J.E.; Patrick, M.E. Monitoring the Future National Survey Results on Drug Use, 1975-2018: Overview, Key Findings on Adolescent Drug Use; Institute for Social Research, The University of Michigan: Ann Arbor, MI, USA, 2019; p. 119.

34. Rehm, J.; Taylor, B.; Room, R. Global burden of disease from alcohol, illicit drugs and tobacco. Drug Alcohol Rev. 2006, 25, 503-513. [CrossRef] [PubMed]

35. Busch, V.; Van Stel, H.F.; Schrijvers, A.J.P.; de Leeuw, J.R.J. Clustering of health-related behaviors, health outcomes and demographics in Dutch adolescents: A cross-sectional study. BMC Public Health 2013, 13, 1118. [CrossRef]

36. Pronk, N.P.; Anderson, L.H.; Crain, A.L.; Martinson, B.C.; O'Connor, P.J.; Sherwood, N.E.; Whitebird, R.R. Meeting recommendations for multiple healthy lifestyle factors. Prevalence, clustering, and predictors among adolescent, adult, and senior health plan members. Am. J. Prev. Med. 2004, 27, 25-33. [CrossRef]

37. Pronk, N.P.; Peek, C.J.; Goldstein, M.G. Addressing multiple behavioral risk factors in primary care. A synthesis of current knowledge and stakeholder dialogue sessions. Am. J. Prev. Med. 2004, 27, 4-17. [CrossRef] [PubMed]

38. Werch, C.C.; Moore, M.J.; DiClemente, C.C.; Bledsoe, R.; Jobli, E. A multihealth behavior intervention integrating physical activity and substance use prevention for adolescents. Prev. Sci. 2005, 6, 213-226. [CrossRef]

39. Centers for Disease Control and Prevention. YRBSS-Questionnaires 2017. 2017. Available online: http://www.cdc.gov/ healthyyouth/data/yrbs / questionnaires.htm (accessed on 7 September 2019).

40. Scott, J.J.; Morgan, P.J.; Plotnikoff, R.C.; Lubans, D.R. Reliability and validity of a single-item physical activity measure for adolescents. J. Paediatr. Child Health 2015, 51, 787-793. [CrossRef] [PubMed]

41. Lubans, D.R.; Hesketh, K.; Cliff, D.P.; Barnett, L.M.; Salmon, J.; Dollman, J.; Morgan, P.J.; Hills, A.P.; Hardy, L.L. A systematic review of the validity and reliability of sedentary behaviour measures used with children and adolescents. Obes. Rev. 2011, 12, 781-799. [CrossRef]

42. Schmitz, K.H.; Harnack, L.; Fulton, J.E.; Jacobs, D.R., Jr.; Gao, S.; Lytle, L.A.; Van Coevering, P. Reliability and Validity of a Brief Questionnaire to Assess Television Viewing and Computer Use by Middle School Children. J. Sch. Health 2004, 74, 370-377. [CrossRef] [PubMed]

43. Nascimento-Ferreira, M.V.; Collese, T.S.; de Moraes, A.C.F.; Rendo-Urteaga, T.; Moreno, L.A.; Carvalho, H.B. Validity and reliability of sleep time questionnaires in children and adolescents: A systematic review and meta-analysis. Sleep Med. Rev. 2016, 30, 85-96. [CrossRef] [PubMed]

44. Goodman, E.; Adler, N.E.; Kawachi, I.; Frazier, A.L.; Huang, B.; Colditz, G.A. Adolescents' perceptions of social status: Development and evaluation of a new indicator. Pediatrics 2001, 108, E31. [CrossRef] [PubMed]

45. World Health Organization. WHO Anthro (Version 3.2.2) and Macros; World Health Organization: Geneva, Switzerland, 2011.

46. Dancey, C.; Reidy, J. Statistics without Maths for Psychology, 6th ed.; Pearson Education Limited: London, UK, 2014.

47. Janssen, I.; Roberts, K.C.; Thompson, W. Is adherence to the Canadian 24-h Movement Behaviour Guidelines for Children and Youth associated with improved indicators of physical, mental, and social health? Appl. Physiol. Nutr. Metab. 2017, 42, 725-731. [CrossRef]

48. McCormick, E.M.; Qu, Y.; Telzer, E.H. Adolescent neurodevelopment of cognitive control and risk-taking in negative family contexts. Neuroimage 2016, 124, 989-996. [CrossRef]

49. Allen, J.P.; Moore, C.; Kuperminc, G.; Bell, K. Attachment and adolescent psychosocial functioning. Child Dev. 1998, 69, 1406-1419. [CrossRef] [PubMed]

50. Adachi-Mejia, A.M.; Primack, B.A.; Beach, M.L.; Titus-Ernstoff, L.; Longacre, M.R.; Weiss, J.E.; Dalton, M.A. Influence of Movie Smoking Exposure and Team Sports Participation on Established Smoking. Arch. Pediatrics Adolesc. Med. 2009, 163, 638-643. [CrossRef]

51. Kujala, U.M.; Kaprio, J.; Rose, R.J. Physical activity in adolescence and smoking in young adulthood: A prospective twin cohort study. Addiction 2007, 102, 1151-1157. [CrossRef] [PubMed] 
52. Audrain-McGovern, J.; Rodriguez, D. All physical activity may not be associated with a lower likelihood of adolescent smoking uptake. Addict. Behav. 2015, 51, 177-183. [CrossRef] [PubMed]

53. Holmen, T.L.; Barrett-Connor, E.; Clausen, J.; Holmen, J.; Bjermer, L. Physical exercise, sports, and lung function in smoking versus nonsmoking adolescents. Eur. Respir. J. 2002, 19, 8. [CrossRef]

54. Wong, M.M.; Robertson, G.C.; Dyson, R.B. Prospective relationship between poor sleep and substance-related problems in a national sample of adolescents. Alcohol. Clin. Exp. Res. 2015, 39, 355-362. [CrossRef]

55. Chaput, J.-P.; McNeil, J.; Després, J.-P.; Bouchard, C.; Tremblay, A. Short sleep duration is associated with greater alcohol consumption in adults. Appetite 2012, 59, 650-655. [CrossRef]

56. Grube, J.W.; Waiters, E. Alcohol in the media: Content and effects on drinking beliefs and behaviors among youth. Adolesc. Med. Clin. 2005, 16, 327-343. [CrossRef]

57. Chen, M.J.; Grube, J.W.; Bersamin, M.; Waiters, E.; Keefe, D.B. Alcohol advertising: What makes it attractive to youth? J. Health Commun. 2005, 10, 553-565. [CrossRef]

58. Henriksen, L.; Feighery, E.C.; Schleicher, N.C.; Fortmann, S.P. Receptivity to alcohol marketing predicts initiation of alcohol use. J. Adolesc. Health 2008, 42, 28-35. [CrossRef]

59. Anderson, P.; de Bruijn, A.; Angus, K.; Gordon, R.; Hastings, G. Impact of alcohol advertising and media exposure on adolescent alcohol use: A systematic review of longitudinal studies. Alcohol Alcohol. 2009, 44, 229-243. [CrossRef]

60. McClure, A.C.; Stoolmiller, M.; Tanski, S.E.; Worth, K.A.; Sargent, J.D. Alcohol-branded merchandise and its association with drinking attitudes and outcomes in US adolescents. Arch. Pediatr. Adolesc. Med. 2009, 163, 211-217. [CrossRef]

61. Jones, S.C.; Magee, C.A. Exposure to alcohol advertising and alcohol consumption among Australian adolescents. Alcohol Alcohol. 2011, 46, 630-637. [CrossRef]

62. Grenard, J.L.; Dent, C.W.; Stacy, A.W. Exposure to Alcohol Advertisements and Teenage Alcohol-Related Problems. Pediatrics 2013. [CrossRef] [PubMed]

63. Almeida-Filho, N.; Lessa, I.; Magalhães, L.; Araujo, M.J.; Aquino, E.; Kawachi, I.; James, S.A. Alcohol drinking patterns by gender, ethnicity, and social class in Bahia, Brazil. Rev. Saude Publ. 2004, 38, 45-54. [CrossRef]

64. Mohan, D.; Chopra, A.; Sethi, H. Incidence estimates of substance use disorders in a cohort from Delhi, India. Indian J. Med. Res. 2002, 115, 128-135.

65. Schulte, M.T.; Ramo, D.; Brown, S.A. Gender differences in factors influencing alcohol use and drinking progression among adolescents. Clin. Psychol. Rev. 2009, 29, 535-547. [CrossRef]

66. Johnston, L.D.; O’Malley, P.M.; Bachman, J.G.; Schulenberg, J.E. Monitoring the Future National Results on Adolescent Drug Use: Overview of Key Findings, 2007; (NIH Publication No. 08-6418); National Institute on Drug Abuse: Bethesda, MD, USA, 2008.

67. Young, S.E.; Corley, R.P.; Stallings, M.C.; Rhee, S.H.; Crowley, T.J.; Hewitt, J.K. Substance use, abuse and dependence in adolescence: Prevalence, symptom profiles and correlates. Drug Alcohol Depend. 2002, 68, 309-322. [CrossRef]

68. Leasure, J.L.; Neighbors, C.; Henderson, C.E.; Young, C.M. Exercise and Alcohol Consumption: What We Know, What We Need to Know, and Why it is Important. Front. Psychiatry 2015, 6, 156. [CrossRef] [PubMed]

69. Choquet, M.; Hassler, C. Sport and alcohol consumption in adolescence. Alcoologie 1997, 19, $21-28$.

70. Lorente, F.O.; Souville, M.; Griffet, J.; Grélot, L. Participation in sports and alcohol consumption among French adolescents. Addict. Behav. 2004, 29, 941-946. [CrossRef] [PubMed]

71. Wichstrøm, T.; Wichstrøm, L. Does sports participation during adolescence prevent later alcohol, tobacco and cannabis use? Addiction 2009, 104, 138-149. [CrossRef] [PubMed]

72. Brellenthin, A.G.; Koltyn, K.F. Exercise as an adjunctive treatment for cannabis use disorder. Am. J. Drug Alcohol Abuse 2016, 42, 481-489. [CrossRef]

73. Wang, H.; Zhong, J.; Hu, R.; Fiona, B.; Yu, M.; Du, H. Prevalence of high screen time and associated factors among students: A cross-sectional study in Zhejiang, China. BMJ Open 2018, 8, e021493. [CrossRef]

74. Schaan, C.W.; Cureau, F.V.; Sbaraini, M.; Sparrenberger, K.; Kohl, H.W., III; Schaan, B.D. Prevalence of excessive screen time and TV viewing among Brazilian adolescents: A systematic review and meta-analysis. J. Pediatr. (Rio J.) 2019, 95, 155-165. [CrossRef]

75. Sampasa-Kanyinga, H.; Hamilton, H.A.; Chaput, J.P. Use of social media is associated with short sleep duration in a dose-response manner in students aged 11 to 20 years. Acta Paediatr. 2018, 107, 694-700. [CrossRef] [PubMed]

76. Hisler, G.; Twenge, J.M.; Krizan, Z. Associations between screen time and short sleep duration among adolescents varies by media type: Evidence from a cohort study. Sleep Med. 2020, 66, 92-102. [CrossRef] [PubMed]

77. Wang, D.; Wang, Y.; Wang, Y.; Li, R.; Zhou, C. Impact of physical exercise on substance use disorders: A meta-analysis. PLoS ONE 2014, 9, e110728. [CrossRef]

78. Doggett, A.; Qian, W.; Godin, K.; De Groh, M.; Leatherdale, S.T. Examining the association between exposure to various screen time sedentary behaviours and cannabis use among youth in the COMPASS study. SSM Popul. Health 2019, 9, 100487. [CrossRef] 